DIREITO À EDUCAÇÃO NA

PANDEMIA: defender a vida e não as prescrições curriculares da BNCC

RIGHT TO EDUCATION IN PANDEMIC: defending life and not the BNCC curriculum prescriptions

\section{DERECHO A LA EDUCACIÓN}

PANDÉMICA: defender la vida y no los requisitos curriculares del BNCC

Resumo: As orientações dos órgãos de gestão pública e de controle social das políticas educacionais para o período emergencial da pandemia têm apresentado soluções burocráticas e padronizadas para dar seguimento ao ano letivo e ao currículo nas redes e sistemas de educação. $O$ presente artigo traz uma análise do cenário da educação com base nas reflexões de coletivos da Educação e do Campo, objetivando colocar em debate como o Estado brasileiro vem negligenciando o direito à educação, tendo em vista a centralidade dada à BNCC e a legitimação do ensino remoto, que enfraquecem a formação humana integral dos estudantes e colaboram, de forma expressiva, para a desresponsabilização do Estado para com as políticas estruturantes que viabilizam a oferta da educação com qualidade, durante e depois da pandemia. Conclui-se que para superar tais contradições, é fundamental que o Estado brasileiro e órgãos de controle social aprofundem a análise sobre as condições efetivas da ofertada da educação na pandemia e ampliem os canais de diálogos com as comunidades e escolas, visando conhecer as diferentes realidades e, assim, construir saídas concretas que assegurem o direito à educação para todos e todas.

Palavras-chave: Pandemia. Currículo. Direito à Educação. Educação do Campo. Ensino Remoto.

Recebido em: 10/03/2021

Alterações recebidas em: 22/05/2021

Aceito em: 22/05/2021

Publicação em: 09/06/2021
Salomão Antônio Hage

Doutor em Educação

Professor da Universidade Federal do Pará,Brasil.

E-mail: salomaohage53@gmail.com

Orcid: https://orcid.org/0000-0002-28591346.

Ivânia Paula Freitas de Souza Sena

Doutora em Educação

Professora da Universidade do Estado da Bahia,Brasil.

E-mail: ipfsouza@uneb.br

Orcid: https://orcid.org/0000-0002-68348842

\section{Como citar este artigo:}

HAGE, S. A; SENA, I. P. F. S. DIREITO À EDUCAÇÃO NA PANDEMIA: Defender a vida e não as prescrições curriculares da BNCC. Revista Espaço do Currículo, v. 14, n. 2, p. 1-14, 2021. ISSN1983-1579. DOI: https://doi.org/10.22478/ufpb.19831579.2021v14n2.58060. 
Abstract: The guidelines of the public management and social control bodies of educational policies for the emergency period of the pandemic have presented bureaucratic and standardized solutions to follow up the school year and the curriculum in education networks and systems. This article presents an analysis of the education scenario based on the reflections of Rural Education collectives, aiming to debate how the Brazilian State has been neglecting the right to education, in view of the centrality given to BNCC and the legitimacy of remote teaching, which weaken the students' integral human formation and collaborate, in an expressive way, for the State's lack of responsibility for the structural policies that make possible the offer of quality education, during and after the pandemic. It is concluded that in order to overcome such contradictions, it is essential that the Brazilian State and social control bodies, deepen the analysis on the effective conditions of the education offer in the pandemic and broaden the dialogue channels with the communities and schools, aiming to know the different realities and, thus, build concrete solutions that ensure the right to education for all.

Keywords: Pandemic. Curriculum. Right to Education. Rural Education. Remote teaching

Resumem: Los lineamientos de los órganos de gestión pública y control social de las políticas educativas para el período de emergencia de la pandemia, han presentado soluciones burocráticas y estandarizadas para el seguimiento del año escolar y el currículo en las redes y sistemas educativos. Este artículo presenta un análisis del escenario educativo a partir de las reflexiones de colectivos de Educación Rural, con el objetivo de debatir cómo el Estado brasileño ha venido desatendiendo el derecho a la educación, ante la centralidad otorgada al BNCC y la legitimidad de la enseñanza a distancia, que debilitan la formación humana integral de los estudiantes y colaboran, de manera expresiva, por la falta de responsabilidad del Estado en las políticas estructurales que hacen posible la provisión de una educación de calidad, durante y después de la pandemia. Se concluye que para superar tales contradicciones, es fundamental que el Estado brasileño y las agencias de control social, profundicen el análisis sobre las condiciones efectivas de la oferta educativa en la pandemia y amplíen los canales de diálogo con las comunidades y escuelas, con el objetivo de conocer las diferentes realidades y, así, construir soluciones concretas que aseguren el derecho a la educación para todos.

Palavras-clave: Pandemia. Currículum. Derecho a la Educación. Educación Rural. Enseñanza remota.

\section{INTRODUÇÃO}

Os desafios que se apresentam ao setor educacional, diante da necessidade de atender as medidas de distanciamento social são gigantescos e o mais urgente consiste em assegurar a continuidade das atividades escolares de forma não presencial, sem prejuízo da qualidade e sem intensificar as desigualdades educacionais e sociais, como tem ocorrido com a implantação precária e intempestiva da EaD e do Ensino Remoto. Desafio hercúleo, considerando os dados da Pesquisa TIC Domicílios (CETIC. BR, 2020), divulgada em agosto de 2019 , que afirma que $70 \%$ da população brasileira possuem acesso à internet, sendo o celular o meio mais utilizado por $97 \%$ dos usuários. Nos territórios urbanos, $74 \%$ têm conexão à internet, enquanto nos territórios rurais, esse número alcançou apenas $49 \%$.

Nas camadas mais pobres de toda a população, $48 \%$ estão conectados à rede, embora o número de domicílios sem acesso à conexão, em o todo o país, seja de 46,5 milhões. $43 \%$ das escolas rurais ainda não têm acesso à internet. Segundo a Agência Brasil (2020), tomando como base os dados da pesquisa Tic Kids online 2019, 4,8 milhões de crianças e adolescentes em todo o Brasil não têm acesso à internet e há um amplo contingente com acesso precário ou falta de equipamento necessário, a exemplo de um computador. Nos territórios rurais, $25 \%$ das crianças e adolescentes não possuem acesso à internet, sendo que nas regiões Norte e Nordeste, esse percentual é de $21 \%$ e, entre os domicílios das classes D e E, 20\%.

Outro grande desafio enfrentado pela educação durante a pandemia tem sido a realidade da maioria das escolas públicas situadas tanto na periferia urbana quanto em territórios quilombolas, indígenas, comunidades tradicionais e camponesas, que apresentam infraestrutura e as condições materiais precárias, com pouca ventilação, banheiros sem higienização, falta de material para limpeza, falta de água potável, de equipamentos e outros insumos necessários para a concretização das atividades educativas, inclusive, o acesso à rede de internet, computadores, energia elétrica, entre outros fatores necessários para que a educação seja ofertada com qualidade socialmente referenciada, para garantir o 
padrão de qualidade exigido tanto pela atual LDB (Art. $3^{\circ}$, Inciso IX) quanto pela Constituição Federal (Art. 206, Inciso VII).

Temos constatado, a partir de nossas reflexões e participação no debate nacional e local sobre o papel da Educação durante a pandemia, que as orientações definidas pelos órgãos de gestão pública (Ministério da Educação - MEC e secretarias estaduais e municipais) e de controle social das políticas educacionais (Conselho Nacional de Educação - CNE e conselhos estaduais e municipais) neste período emergencial, apresentam soluções burocráticas e padronizadas, que centralizam o foco na transmissão de conteúdos, prescritos pela BNCC, de forma não presencial ou de forma híbrida e na reorganização do calendário escolar, para fins de cumprimento da carga horária mínima anual, suscitando preocupações, inquietudes e ansiedades nos educadores, estudantes e seus familiares, especialmente porque não são acolhedoras das demandas, necessidades e interesses desses seguimentos.

De fato, as soluções apresentadas pelos órgãos de gestão pública e de controle social das políticas educacionais, em grande medida, possuem caráter profundamente excludente e potencialmente produtor de desigualdades educacionais em relação às crianças, adolescentes, jovens e adultos das classes trabalhadoras e populares que estudam nas escolas públicas, nas quais se incluem os povos tradicionais, quilombolas, indígenas e camponeses já privados historicamente do direito à educação de qualidade, como tem sido denunciado e enfrentado há pelo menos 20 anos pelo Movimento da Educação do Campo no Brasil (FONEC, 2020).

Essas orientações e soluções seguem ignorando que a educação brasileira é constituída de uma pluralidade de contextos socioculturais definidos pelas diversidades econômicas, geográficas, climáticas e culturais, entre outras, que são próprias deste país de dimensões continentais; como também, que existem amplas desigualdades econômicas, de raça, de gênero, de sexualidade, de religiosidade, de territorialidade, de geração, entre outras que requerem responsabilidade política e social dos governos, dos conselhos, das escolas e demais espaços educativos, para pautarem políticas públicas e estratégias educativas e curriculares afirmativas da diferença e da igualdade, que confrontem com a uniformização e as desigualdades, em tempos de pandemia ou não.

No cerne dessas orientações e soluções prevalecem os interesses dos setores privatistas e conservadores, interessados na mercantilização da educação pública, que há anos lucram, porque lideram essa concepção padronizada e homogeneizadora de educação e de currículo, como bem sinalizou o processo de definição da Base Nacional Comum Curricular da Educação Básica e da Base Nacional de Formação de Professores, sob a liderança do Movimento Todos pela Educação no CNE. Instrumentos esses, que são coerentes com os projetos de educação e de currículo que se colocam a serviço do mercado e não se furtam em afirmar sua satisfação em restringir as finalidades da educação à aprendizagem, e do ensino à transmissão de conteúdos escolares; e nem tampouco, de aceitar sem pesar, que milhões de estudantes sejam excluídos, mesmo que desse acesso restrito por eles estabelecido como parâmetro de resultados educacionais.

São esses aspectos que trataremos neste artigo, que busca explicitar como o Estado brasileiro vem negligenciando o direito à educação e como, num contexto de acirramento das imposições do mercado sobre o setor educacional, a vida torna-se um bem relativizado diante da necessidade de dar continuidade aos conteúdos curriculares que focam as aprendizagens essenciais, requeridas pelas competências e habilidades impostas pela BNCC.

\section{COVID-19, O DESGOVERNO E A INOPERÂNCIA DO MEC E A QUESTÃO CURRICULAR}

O Brasil e o mundo enfrentam uma grave crise sanitária e econômica com a expansão da pandemia da Covid-19, que interrompeu o curso da vida das pessoas e vem desafiando a lógica individual e mercantil de organização da sociedade em escala local e global. A pandemia vem colocando à prova tanto a capacidade do mercado se autorregular quanto a teoria do estado mínimo, que configura a base das políticas neoliberais e impõe a diminuição das responsabilidades e investimentos do Estado em políticas sociais, como saúde e educação.

Essa situação, no entendimento da Organização Mundial de Saúde(OMS), exige a responsabilidade 
coletiva para a eficácia das medidas de distanciamento social, enquanto não há vacina para todos. E ao mesmo tempo, tem forçado os governos de inúmeros países a intervirem nas economias nacionais, retomando os investimentos na área da saúde para tentar conter o crescimento acelerado dos contágios e mortes, bem como, a falência de muitas empresas durante a pandemia e a consequente intensificação da miséria.

No Brasil, o governo federal não priorizou a efetivação de políticas proativas de controle e atuação sobre a pandemia. O que se viu foi um conjunto de ações opostas aos demais países, no que diz respeito às medidas de distanciamento social, ações de fortalecimento do sistema público de saúde (desde a garantia dos insumos básicos, até o investimento em pesquisas e a aquisição de vacinas) e, sobretudo, quanto a um planejamento político capaz de minimizar os efeitos da instabilidade econômica, que afetou mais drasticamente as famílias das camadas sociais mais vulneráveis, alcançando as empresas e diversos setores do comércio.

Nesse cenário de calamidade pública, o Fórum Nacional de Educação do Campo (FONEC), coletivo que representa o Movimento da Educação do Campo no Brasil - integrado por fóruns e comitês estaduais, regionais e municipais de Educação do Campo; movimentos e organizações sociais dos povos tradicionais e camponeses; universidades e redes de ensino, organizações governamentais e não governamentais tem se mantido vigilante assumido posição firme em defesa da vida em condições dignas essenciais à manutenção da existência humana, referenciando-se pelo que determina a Constituição Federal de 1988 (Art. $1^{\circ}, \mathrm{III}$ ): a dignidade da pessoa humana, como um dos fundamentos da República e pedra angular de nosso Estado Democrático de Direito.

Os povos do campo, das águas e da floresta - agricultores; assentados; acampados; ribeirinhos; pescadores; extrativistas; quilombolas; indígenas; seringueiros; quebradeiras de coco; geraizeiros; cerratenses, entre outros - ainda que invisibilizados nas medidas econômicas, sanitárias e educacionais adotadas durante o enfrentamento da pandemia, cumprem um papel histórico na defesa da natureza e dos direitos humanos. Seus saberes, formas de trabalho e de produção, práticas culturais ancestrais e de organizações sociais ensinam-nos o valor dos processos ecológicos que sustentam a continuidade da vida e reafirmam a importância da terra, água, floresta e biodiversidade como bens comuns em prol da saúde, educação e da produção de alimentos saudáveis (SANTOS, et al, 2020).

Diversas instituições da sociedade civil, organizações das classes trabalhadoras e dos povos tradicionais e camponeses, comprometidas com um projeto de sociedade baseado na cooperação, têm protagonizado inúmeras iniciativas de solidariedade, cuidando das pessoas, especialmente das famílias em situação de risco alimentar, nas periferias das cidades, com a realização de campanhas de aquisição de produtos alimentares agroecológicos, produzidos nos assentamentos por meio da agricultura familiar camponesa.

O FONEC (2020) tem cobrado dos governos, em suas distintas esferas, que tomem de volta a autonomia constitucionalmente assegurada para que, de posse dela, possam desenhar ações de suporte às famílias dos milhares de estudantes que necessitam da presença qualificada das escolas. E neste período de pandemia tem apontado duas questões importantes: 1) o direito fundamental à educação, subordinando-se ao princípio da dignidade da pessoa humana, deve, enquanto durar o estado de calamidade pública, ser totalmente exercido e exercitado para defesa da vida; 2) a permaneçam fechadas até que se assegure a vacina, uma vez que ela é a possibilidade mais segura de retorno às atividades educativas presenciais, com menor risco à vida dos profissionais e dos estudantes.

O Fórum de Educação do Estado da Bahia também se posicionou em nota pública, afirmando ser necessário garantir a realização de atividades escolares não presenciais como forma de assegurar tanto o direito à vida quanto o direito à educação, exigindo, inclusive, que "a preparação, organização das condições e planejamento sejam realizados com a participação ativa dos profissionais, estudantes e suas famílias". (FEEBA, 2021).

Partimos da compreensão de que, neste período pandêmico, os sistemas de ensino devem apoiar e dar suporte aos alunos e famílias, e para isto, é fundamental que as escolas se mantenham mobilizadas tendo como horizonte, sua função social: mediar as relações interpessoais nos espaços familiares 
comunitários, fortalecendo valores como a empatia, a responsabilidade individual e coletiva com a higiene, com o distanciamento social e com a solidariedade, valores esses, que são indispensáveis para minimizar a capacidade de expansão do vírus e os efeitos da instabilidade socioeconômica que nos atinge.

Com isso estamos afirmando que o papel da escola durante a pandemia é de colocar em prática um currículo que oportunize o acesso ao conhecimento qualificado aos estudantes, focando na circulação de informações e no incentivo a estudos e práticas que auxiliem no combate às Fake News e às posturas negacionistas que colaboraram diretamente para o atual quadro de mais de 250 mil mortes. Isso exige pensar uma proposta curricular que, pautada no conhecimento histórico acumulado (conhecimento científico, saberes tradicionais e da ancestralidade dos diferentes povos), reafirme os direitos humanos e seja colaborativa para com o enfrentamento dos desafios impostos à vida durante e pós a pandemia.

Desse modo, há muito a ser feito na educação agora e depois que o momento pandêmico passar, mas obviamente, não dá para seguir com o currículo, negando o contexto social mundial, os desafios impostos ao Brasil para superar o quadro da pandemia e a realidade desigual e dura em que vivem os estudantes. Assim, não se pode fazer a defesa por um retorno presencial sem que a vida, bem maior, esteja protegida, como também não se pode dar continuidade ao currículo escolar, ignorando tais questões.

Neste período emergencial, os coletivos em defesa da educação pública, dentre eles, o FONEC, defendem que os recursos públicos sejam total e integralmente mobilizados para que os sistemas de ensino tenham condições de promover um processo educativo, inspirado nos ideais de solidariedade humana e tendo por finalidade o pleno desenvolvimento do educando, conforme estabelece a LDB (Art. $2^{\circ}$ ). Nesse sentido, o processo educativo, diante do contexto pandêmico, deve se estruturar considerando as complexas dimensões da formação integral dos estudantes e buscar garantir um maior suporte para lidar com os efeitos do isolamento social, o qual exerce grande influência sobre as emoções e as relações intra e interpessoais nas crianças, adolescentes, jovens, adultos e idosos.

A abstenção do governo federal de tratar a pandemia com a devida relevância por ela requerida é evidenciada pela ausência do Ministério da Educação na efetivação de políticas e ações educacionais neste momento de emergência. Tal situação pode ser proposital, no sentido de favorecer as iniciativas que têm sido tomadas pelo Conselho Nacional de Educação (CNE), sob a liderança do Movimento Todos Pela Educação, as quais seguem caminho contrário às orientações estabelecidas: pela LDB (Art. $\left.3^{\circ}, 1\right)$, de "assegurar igualdade de condições para o acesso e permanência na escola"; e pela Constituição Brasileira (Art. $3^{\circ}$, III), "de erradicar a pobreza e a marginalização e reduzir as desigualdades sociais e regionais".

Focadas em questões pontuais, como: a reorganização do calendário escolar e reposição das aulas por atividades pedagógicas não presenciais (com ou sem mediação tecnológica) e orientações aos pais para realização de atividades relacionadas aos objetivos de aprendizagem e habilidades prescritas pela BNCC, as orientações definidas pelo CNE legitimam um modelo educacional centrado no repasse de conteúdo como estratégia para dar prosseguimento às atividades da escola e da educação neste período de pandemia, pouco se importando com a realidade desigual e multifacetada da Educação brasileira, pública e privada; as profundas dificuldades e limitações de caráter logístico e de infraestrutura que marcam as diferenças regionais, bem como, do campo e cidade, em todo território nacional.

As escolas, em uma força tarefa com a sociedade em geral, bem como, com os diversos povos, grupos e coletivos sociais organizados, precisam envidar esforços para que o Estado garanta ações emergenciais de proteção social e humanitária que respeitem a saúde, a vida e os direitos das populações mais vulneráveis, com respostas concretas às necessidades mais prementes, que incluem os programas de transferência de renda com um valor substancial para atendimento das necessidades essenciais da vida, de proteção ao emprego, à moradia, de acesso à água potável, aos insumos básicos, assistência médica.

Nesse conjunto de pautas, é fundamental que essa força tarefa reivindique ao Estado brasileiro, através do Ministério da Educação, que se assegure (com a contrapartida com os governos estaduais e municipais) uma política de financiamento emergencial aos sistemas de ensino, para garantia do acesso 
dos estudantes e professores às tecnologias da informação e comunicação - TIC, (computador e internet com qualidade) como condição primeira, para as escolas cumprirem seu papel no período pandêmico.

O que estamos reforçando é que o Estado precisa reconhecer a educação como um direito de todos e como seu dever, conforme assinala a Constituição, e instituir uma política pública de acesso gratuito dos profissionais da educação e estudantes às tecnologias digitais que são, no atual momento, a única forma de as escolas manterem um vínculo educativo com os estudantes. Contudo, colada a essa necessidade urgente, é preciso que a política de financiamento amplie seu alcance para dar a garantia de os sistemas de ensino prepararem as escolas para o ensino presencial pós vacina.

Segundo apontam os cientistas, todas as atividades sociais após a vacina, ainda vão requerer a permanência dos protocolos de segurança, especialmente, por constatar-se que a mutação do vírus que se apresenta em versão mais contagiosa, podendo atingir quem já foi contagiado pelo Covid-19 ou mesmo quem já foi vacinado. Essa informação, divulgada em fevereiro de 2021 no site da CNN Brasil, pelo governo Britânico, aponta que "a variante Bristol é mais transmissível que a variante britânica identificada anteriormente". O site também trouxe uma entrevista da cientista Sharon Peacock, chefe do programa de vigilância genética Covid-19 Genomics UK, pontuando que, devido ao "sequenciamento de variantes do novo coronavírus, pode ser necessário pelo menos 10 anos, até que seja possível controlar o vírus". (CNN BRASIL, 2021). Dois dias depois da entrevista, o mesmo site divulgou a confirmação de dois casos da variante britânica no estado de Goiás, nos municípios de Luziânia e Valparaíso. Portanto, não sabemos ao certo o que está por vir e o Governo Federal deve ser cobrado a agir, especialmente, no tocante à educação, tão essencialmente vital nesse momento.

Mesmo atingindo toda a sociedade brasileira e mundial, a pandemia revelou um quadro dramático em escala global, mas seus efeitos não afetam todas as pessoas da mesma forma. As populações mais vulneráveis são, obviamente, mais gravemente atingidas e as consequências ainda são impossíveis de serem mensuradas. Entre estes coletivos, incluem-se, como ressalta o FONEC (2020), os que vivem em situação de pobreza extrema, na informalidade ou com contratos temporários e precarizados de trabalho; os idosos, a população em situação de rua, em privação de liberdade, os refugiados, os povos indígenas, quilombolas, extrativistas, ribeirinhos, assentados e acampados que vivem da agricultura familiar, dentre outros que historicamente ficaram à margem da prioridade do Estado.

A situação de invisibilidade desses povos foi escancarada no contexto pandêmico e, na educação, ela tem se revelado pelas precárias ou inexistentes condições dos estudantes acessarem a escola, da única forma possível, a virtual. Por isso reiteramos a defesa de que os recursos públicos destinados à educação, neste período devem ser mobilizados para: a) apoiar os estudantes e suas famílias a fim de garantir eficácia às medidas de isolamento, especialmente, aquelas que se encontram em situação de vulnerabilidade social; b) assegurar o emprego e o salário dos educadores enquanto durar a pandemia; garantir alimentação de qualidade, pela continuidade do repasse dos recursos do Programa Nacional de Alimentação Escolar pela União a estados e municípios, para a sua aquisição enquanto as escolas estiverem sem funcionamento presencial; e c) democratizar o acesso às tecnologias da informação e comunicação por parte de todos os estudantes das redes públicas, com atendimento prioritário às comunidades de baixa renda, aos povos indígenas, quilombolas e camponeses. Essas são algumas das prioridades a serem viabilizadas com os recursos da educação.

Decerto, somente a união de esforços entre as entidades da área educacional, movimentos sociais e sindicais gerais e da educação, instituições de ensino da Educação Básica e Superior, professores, estudantes e seus familiares, pode convergir para a superação dos grandes desafios que humanidade está vivenciando neste período emergencial, em que o distanciamento social apresenta-se como a principal medida para proteger a vida. Todos estamos sendo convocados a colaborar com esta frente em defesa do direito à educação para que ele seja assumido pelo Estado brasileiro, pelos governos, cumprindo um preceito constitucional que ao nosso ver é irrevogável.

\section{O ENSINO REMOTO, A BNCC E A PRECARIZAÇÃO DA ESCOLA E DA FORMAÇÃO DOS ESTUDANTES}

Antes de a pandemia colocar-nos em isolamento e acentuar a presença das tecnologias digitais no cotidiano das escolas, o Governo Bolsonaro, através do Ministério da Mulher, da Família e dos Direitos 
Humanos apresentou no ano de 2019, um projeto de lei para regulamentar o ensino doméstico. 0 argumento da proposta assentava-se no fato de os pais terem o direito de educarem seus filhos, assegurando seus princípios e valores, sobretudo, morais e religiosos.

O que o governo federal propunha, embora o projeto não tenha seguido adiante em âmbito nacional devido à rejeição de vários setores da educação, está diretamente ligado ao processo de precarização da educação pública e do afastamento gradativo do Estado, da oferta do direito à Educação de qualidade, que tem se acentuado nos últimos anos. Um dos elementos do combate a essa proposta era o fato de que o ensino doméstico abriria vários precedentes, um deles seria a desobrigação do poder público de construir e manter escolas para todos, o que favoreceria a ampliação das desigualdades, uma vez que, aqueles que dispõem de melhores condições financeiras, teriam maior suporte com professores particulares, deixando ao largo do direito, a grande maioria dos estudantes.

Ademais, como bem sinalizou a Carta aberta em defesa da Educação democrática: contra projetos de censura à educação nacional (2018), há um equívoco em afirmar "que a escolarização deve se guiar somente pela vontade e concepções morais de indivíduos e famílias, destacando que tal posição contraria "o Art. 205 da Constituição Federal, que afirma que a educação é dever conjunto do Estado e da família, sendo promovida com a colaboração da sociedade". Essa proposta, uma vez aprovada, daria suporte ao que alguns municípios já vêm tentando implementar como política, o pagamento de vouchers que permitem a matrícula na escola privada, colocando para o poder público a responsabilidade de apenas arcar com a sua mensalidade.

Para esses gestores, essa é uma "saída" para a redução dos "gastos" na educação, proposição que também se alinha às inúmeras propostas de ampliação da Educação à Distância (EaD), que avança no Ensino Superior e aos poucos vem se implantando na Educação Básica, concebendo-a como um grande nicho de mercado. É bom lembrar que Bolsonaro chegou a falar em EaD, inclusive, para substituir as escolas do campo de anos iniciais multisseriadas, que estão sendo gradativamente fechadas com o avanço da política de nucleação vinculada ao transporte escolar, uma vez que são vistas pelos gestores públicos como um gasto desnecessário.

Outro destaque é que propostas como essas reforçam o empobrecimento da formação integral das crianças em consequência da perda do contato com a diversidade social que constitui a convivência escolar, marcada pela diversidade de culturas, de ideias e pelas desigualdades econômicas dos estudantes e suas famílias. Esse elemento, que para nós representa a riqueza da escola, desaparece no âmbito do ensino doméstico, podendo acentuar o individualismo, a intolerância, o preconceito, o racismo, o negacionismo e o pouco exercício do pensamento crítico. Mas, sobretudo, limita a educação ao ensino-aprendizagem e o currículo ao ensino de conteúdos isolados do contexto sócio histórico, esvaziando seu caráter político de formação humana voltada para a transformação da realidade social.

Esclarecemos que essas questões, também, estão alinhadas aos objetivos que fundamentam o projeto Escola Sem Partido, que defende haver na educação crítica, uma ideologia partidária de esquerda, marxista, que doutrina os estudantes, sendo, portanto, necessário que se implemente um currículo neutro. Na prática, essas posições servem para intensificar as perseguições aos professores e instituições de ensino superior, que defendem sua autonomia e a liberdade de cátedra, asseguradas pelos preceitos constitucionais, e para impedir que a escola e o currículo pautem a diversidade.

Para a Educação do Campo, a referência à diversidade é fundante, sobretudo, porque seus princípios consideram que é a realidade dos sujeitos, dos territórios e as diferentes culturas dos povos do campo, das águas e das florestas, que orienta a organização do trabalho pedagógico e dão vida ao currículo. Nesse sentido, lembram Taffarel e Souza (2020)

O método utilizado deve, portanto, estar embasado na inter-relação entre a teoria e a prática e na produção coletiva do conhecimento por parte dos/as educadores/as, dos/as estudantes, da família e da comunidade. O professor pode motivar a reflexão e incentivar a busca do conhecimento, aprendendo conjuntamente no processo, e a família ser parte integrante na realização das 
ações pensadas. (p. 24)

É nesse contexto que a Base Nacional Comum Curricular - BNCC foi aprovada e implementada nos sistemas de ensino, numa formatação que fortalece os princípios dessas propostas mercantilizadas e conservadoras, e segue na contramão dos preceitos legais e constitucionais. No processo de padronização do currículo em sequências de habilidades com foco em dez competências, a BNCC homogeneíza os processos escolares, secundarizando a diversidade e retirando de pauta a perspectiva crítica da formação dos estudantes. Desse modo, ela confisca a autonomia dos sistemas de ensino, das escolas e dos professores de decidir sobre seus processos pedagógicos e formativos.

A BNCC viola as conquistas legais que asseguram o direito à diversidade, a pluralidade de culturas e ideias, a liberdade de ensinar e aprender e de concepções pedagógicas, previstas nos artigos 206 e 215 da Constituição Federal, no artigo $3^{\circ}$ da LDB, no Plano Nacional de Educação, nas Diretrizes Curriculares para a Educação Básica - DCN de 2013. As Diretrizes reconhecem ser necessário

Problematizar o desenho organizacional da instituição escolar, que não tem conseguido responder às singularidades dos sujeitos que a compõem. Torna-se inadiável trazer para o debate os princípios e as práticas de um processo de inclusão social, que garanta o acesso e considere a diversidade humana, social, cultural, econômica dos grupos historicamente excluídos. Trata-se das questões de classe, gênero, raça, etnia, geração, constituídas por categorias que se entrelaçam na vida sociais - pobres, mulheres, afrodescendentes, indígenas, pessoas com deficiência, as populações do campo, os de diferentes orientações sexuais, os sujeitos albergados, aqueles em situação de rua, em privação de liberdade - todos que compõem a diversidade que é a sociedade brasileira e que começam a ser contemplados pelas políticas públicas. (MEC, 2013, p. 16)

Em sintonia com esses importantes marcos, a Educação do Campo tem na sua base legal e teórica, outros elementos que justificam seu antagonismo à BNCC, dentre eles:

compreensão da cultura como matriz do conhecimento; valorização da identidade da escola, por meio da garantia de projetos político-pedagógicos com organização curricular e metodologias adequadas às necessidades dos estudantes do campo; compreensão do trabalho como princípio formativo (o que significa pensar a formação pelo trabalho humano numa perspectiva emancipatória, no sentido de analisar, conhecer e transformar a natureza para o bem-estar e desenvolvimento da sociedade); garantia de projetos educativos com pedagogias condizentes com as condições e anseios das populações do campo; e a flexibilização na organização escolar, visando à adequação do tempo pedagógico, à definição do calendário. (TAFFAREL; SOUZA, 2020, p. 24)

A padronização curricular imposta pela BNCC desconsidera esses elementos e segue impondo habilidades sequenciadas que possuem centralidade no documento e restringem a relevância das áreas de conhecimento, a partir dos seus objetivos. O documento constitui-se um guia ou manual do trabalho docente, que direciona para a aplicação de uma sequência ininterrupta e linear de procedimentos e conteúdos que, supostamente, resultará nas aprendizagens essenciais: as dez competências que, na BNCC integram os objetivos de toda a formação básica dos estudantes.

Contudo, reiteramos que, tal sequenciamento provoca o distanciamento da escola e de suas práticas da realidade das comunidades, restringindo o processo educativo ao ensino de conteúdos que interessam aos seus formuladores, os empresários da educação. As reformas em curso, como aponta Felipe (2020, p. 81) “[...] imprimiram formas de ajustamento da educação às novas exigências econômicas globais nas mais diferentes ordens: jurídico-normativa, curricular e de governança, necessárias ao pleno cumprimento de seus objetivos".

A BNCC instituiu, através do "direito à aprendizagem", uma ampla mobilização dos sistemas de ensino para o controle do processo formativo dos estudantes, restringindo-o à aprendizagem de 
competências que reforçam os valores dos grupos que passaram a definir hegemonicamente as políticas de Educação no Brasil, liderados pelo Movimento Todos pela Educação.

Sob a nossa perspectiva, torna-se fundamental, portanto, a compreensão de que os objetivos introduzidos na política de educação brasileira pela BNCC, decorrem de um poderoso movimento de ajuste da educação aos interesses do capital, que vem se fortalecendo desde o final da década de 1990.

A padronização de conhecimentos, habilidades e competências induzida pelas Matrizes de Referência do Saeb e formalizada pela Base Nacional Comum Curricular representou, do ponto de vista da agenda global, a consolidação de um ciclo de reformas educativas, erigidas de orientações políticas mais amplas, que articulam conhecimento técnico-científico e doutrinas político-econômicas de ajustamento e de contenção da subversão, à atual ordem que vem governando a existência coletiva nos países centrais e periféricos do capitalismo. (FELIPE, 2020, p. 90)

Por meio desse movimento hegemônico protagonizado pelos grupos empresariais como estratégia para avançar com a mercantilização da Educação, a pauta do direito à Educação, historicamente assumida por inúmeros fóruns e movimentos de caráter popular, a exemplo da Campanha Nacional pelo Direito à Educação, o Fórum Nacional Popular de Educação, o Fórum Nacional de Educação do Campo (FONEC), a Associação Nacional pela Formação dos Profissionais da Educação (ANFOPE), a Associação Nacional de Pós-Graduação e Pesquisa em Educação (ANPEd), Sindicato Nacional dos Docentes das Instituições de Ensino Superior (ANDES-SN), Rede Autonomia e Diversidade na Educação Pública (REDAP) entre outros, tem sido negligenciada e as "aprendizagens essenciais" (habilidades e competências) por eles prescritas, passaram a restringir e enfraquecer o papel social da escola nas comunidades e territórios, e a autonomia intelectual dos professores e professoras.

Importante esclarecer ainda, que todo esse processo tem sido efetivado com a colaboração do Conselho Nacional de Educação (CNE), e com o respaldo do Conselho Nacional de Secretários de Educação (CONSED) e da União Nacional dos Dirigentes Municipais de Educação (UNDIME), sedentos por fortalecer a parceria público-privada como estratégia para a implementação das políticas práticas educacionais e curriculares, sobretudo, neste período em que a pandemia acomete-nos e a EaD, o ensino remoto e o ensino híbrido naturalizam-se, no âmbito dos sistemas de ensino, da Educação Básica e Superior, a despeito da herança negativa que tem imprimido, ao fortalecer a desqualificação dos processos educativos e as desigualdades socioeducacionais.

Tendo em vista que "a Base Nacional Comum Curricular, produzida sob o ideário da modernização conservadora, legitima padrões educacionais de utilidade bastante restrita e de longa data assimilados pelo Saeb" (FELIPE, 2020, p. 94), o modelo remoto do ensino acaba não encontrando muitas dificuldades para se expandir, uma vez que todo processo educativo fica restrito ao ensino e esse, por sua vez, resumese à transferência de conteúdo. Felipe (2020, p. 94) é assertiva ao avançar na análise da BNCC, apontando que

A organização pedagógica com base em competências reduz e simplifica processos de aprendizagem para torná-los mensuráveis, ao mesmo tempo, universaliza expectativas de aprendizagem que são indiferentes às culturas e às suas demandas práticas. Pressupõe, portanto, que atitudes e valores, habilidades e competências são formas fixas, não contextuais, e que as demandas do mundo do trabalho, bem como, do exercício da cidadania, são generalizáveis e configuram a única possibilidade de realização humana, individual ou coletiva.

O formato linear de sequência de habilidades e competências da BNCC é muito favorável ao modelo remoto, que despreza outros elementos formativos, que estão presentes no contexto escolar, e centra os objetivos da educação ao cumprimento dos "objetivos de aprendizagem" que levarão às avaliações de larga escala. Essas, por sua vez, ao exigirem como indicadores de qualidade somente os conteúdos 
relativos às competências da BNCC encerram aí o debate da qualidade da educação, restringindo-a à "aquisição" das chamadas "aprendizagens essenciais" da BNCC. Saviani e Marsiglia (2021, p. 38) chamam a atenção que

A expressão ensino remoto passou a ser usada como alternativa à educação a distância (EAD). Isso, porque a EAD já tem existência estabelecida, coexistindo com a educação presencial como uma modalidade distinta, oferecida regularmente. Diferentemente, o "ensino" remoto é posto como um substituto excepcionalmente adotado neste período de pandemia, em que a educação presencial se encontra interditada.

O próprio CNE tem evitado o uso do termo EaD, especialmente, por conta de essa modalidade ter uma regulamentação legal e a previsão de um percentual de carga horária presencial. $O$ ensino remoto surge, portanto, como versão que, de certo modo, atropela a legislação, à medida que o formato escolar com $100 \%$ de atividades não presenciais acaba sendo validado como forma de dar continuidade aos objetivos da educação. Outros termos aparecem nesse mesmo intuito, ensino on-line; "ensino por meio de Tecnologias Digitais de Informação e Comunicação (TDIC), Calendário Complementar, Estudo Remoto Emergencial etc." (ANDES-SN, 2020, p. 12-13).

Diante da naturalização do ensino remoto como única alternativa a ser utilizada nos sistemas de ensino neste período pandêmico, temos assistido a um intenso processo de negligência com a formação/escolarização dos estudantes. Redes de ensino públicas e escolas privadas adotaram medidas diversas que não levam em conta fatores como a falta de acesso e as condições precárias de conexão com a internet; a inapropriação pedagógica dos dispositivos disponíveis pelos estudantes e professores, como a exemplo do celular; bem como, as questões de saúde, socioeconômicas e psicológicas decorrentes do contexto pandêmico.

Muitas escolas públicas e privadas estão agindo como se o ensino remoto não se diferenciasse das condições de efetivação do ensino presencial, e com isso sobrecarregam os alunos com aulas e atividades, desconsiderando o tempo excessivo de exposição às telas; as questões emocionais e vários tipos de adoecimento que o isolamento social provoca, sobretudo, em crianças, adolescentes e jovens, além da alteração da rotina familiar e no ambiente de aprendizagem que incidem diretamente nos resultados do processo educativo.

Além disso, estamos testemunhando os defensores do ensino remoto produzirem e fazerem circular uma ampla narrativa ilusória de sua viabilidade, assentada na manipulação de dados demonstrativos do cumprimento de dias letivos, de número de alunos alcançados pelas atividades remotas e, principalmente, de garantia dos objetivos da educação, com a aprendizagem por parte dos estudantes.

Na prática, o que se configura em todo o país, é um descompromisso autorizado com a formação humana integral das crianças, adolescentes e jovens, que se concretiza com a redução do processo de escolarização: à transmissão de vídeo-aulas desconectadas de um planejamento articulado ao projeto político-pedagógico da escola, e indiferentes à relação professor-aluno; à aplicação de sequências de conteúdos em encontros síncronos, no qual a aula se resume a leitura de slides, na melhor representação da validação da educação bancária, como bem assinalou Freire (2005); ao envio de blocos ou cadernos de conteúdo impressos, com atividades e exercícios das várias áreas de conhecimento a serem resolvidos e fixados, semanalmente, quinzenal ou mensalmente pelos estudantes das periferias urbanas e das comunidades tradicionais e camponesas, desprovidos de qualquer assistência mais responsável do Estado; ou mesmo, a programas de rádio ou TV que, ainda que se configurem um esforço das redes de ensino para alcançarem um número maior de estudantes, cumprem apenas parte dos objetivos da escola e do processo educativo.

Contudo, mesmo ciente de que todo o esforço sequer dá conta de objetivos parciais da educação, algumas escolas seguem com o ensino remoto e forjam processos cujos resultados são muito pouco convincentes. $\mathrm{Na}$ prática, esses resultados servem como marketing para determinados gestores educacionais afirmarem sua eficiência, ainda que isso signifique a produção de falsos indicadores de 
realidade das escolas nos municípios. Eles, porém, apresentam implicações significativas nas políticas de educação, sobretudo, de financiamento, durante e depois da pandemia. Saviani e Marsiglia (2021) alertam sobre essa situação:

O quadro que se anuncia para o período pós-pandemia trará consigo pressões para generalização da educação a distância, como se fosse equivalente ao ensino presencial, em função dos interesses econômicos privados envolvidos, mas também como resultado da falta de uma verdadeira responsabilidade com a educação pública de qualidade e, ainda, pela apatia de entidades de classe, organizações populares e movimentos sociais ditos progressistas que se renderam ao canto de sereia do ensino virtual. (p. 39)

Em meio a tudo isso, assistimos ainda o avanço de um processo de superexploração dos trabalhadores/as com a implantação do teletrabalho, home office e as atividades no formato remoto em todos os setores da sociedade, acompanhadas pelas propostas governamentais de redução da jornada de trabalho e de salários, demissões ou excesso de atividades diárias, que levam trabalhadores/as ao esgotamento físico e emocional. Na Educação, esses e outros fatores têm agravado a precarização do trabalho docente, como assinalam Crispin e Facci (2020, p. 141).

Na contemporaneidade, com o objetivo de atender às demandas do capital, são criadas formas distintas e sofisticadas de exploração do/a trabalhador/a, materializadas em um intenso processo de precarização do trabalho. Manifesta em várias categorias, a precarização do trabalho se concretiza, também, no âmbito educacional, atingindo os/as professores/as. A flexibilização de contratos, as condições de trabalho, a retirada gradativa dos direitos sociais, dentre outros aspectos, contribui para a intensificação do trabalho desta categoria profissional, bem como para seu adoecimento e, consequentemente, para o afastamento dos seus postos de trabalho.

De fato, este processo de precarização tem provocado, não apenas o desânimo de professores/as com a educação, como tem produzido inúmeras formas de alienação e adoecimento que os apartam das atividades docentes e fragiliza a organização de seus coletivos e entidades de representação. Tais coletivos deveriam estar em luta neste momento da pandemia no qual, o capital e o Estado, através de reformas como a BNCC e da implantação do ensino remoto como caminho para padronização e massificação de resultados, tomam proveito para afirmar seus valores e avançar nas políticas de mercantilização da educação em todas as suas instâncias e sistemas.

\section{CONCLUINDO: o planejamento coletivo como estratégia para garantir o direito à vida e à educação}

Sendo as escolas e salas de aula lugares que agrupam muitas pessoas em ambiente fechado, a retomada de suas atividades cotidianas com segurança, sem ameaçar a vida dos estudantes, educadores e suas famílias, e com os devidos processos de higienização que impeçam a propagação da contaminação pelo vírus, requer fundamentalmente o planejamento prévio entre os órgãos de gestão pública, de forma articulada, acionando o regime de colaboração entre os diferentes entes federativos, com a participação dos educadores, estudantes, pais e comunidades por meio de suas representações e organizações sociais, para o enfrentamento da situação de precarização da infraestrutura das escolas, especialmente nas comunidades tradicionais e camponesas, dotando-as de condições materiais adequadas. É fundamental que se assegure o retorno às escolas, mas que ocorra em ambientes seguros, aptos a atender a comunidade educacional, dispondo de material e pessoal para limpeza e higienização, além de alimentação escolar adequada e suficiente; banheiros, água potável, equipamentos e outros insumos necessários para a concretização das atividades escolares.

Durante e após a pandemia, essa nos parece ser uma condição necessária, mas não suficiente para que as escolas e redes de ensino assumam um papel crucial na formação humana dos sujeitos e na mobilização social, sobretudo, neste período emergencial, para a construção de uma rede de proteção social dos estudantes, educadores e suas famílias. 
É dever do Estado garantir a segurança e a vida de cada cidadão brasileiro. Enquanto não houver vacina para todos, as tecnologias digitais podem ser colaborativas para a educação numa perceptiva mais humana e crítica, conforme sinalizamos. Nesse sentido, elas devem ser vistas como um direito e, portanto, serem asseguradas pelos Governos, de modo que se dê acesso à conectividade. Cabe ao Ministério da Educação, especialmente, constituir uma política de distribuição de notebooks e tabletes para os sistemas de ensino, uma vez que o uso de celular não dá aos estudantes, as condições necessárias para ampliar a relação das tecnologias com as necessidades específicas do processo educativo escolar. No atual contexto, as tecnologias devem ser requeridas para criar a ponte entre estudantes e escolas e, mesmo depois da pandemia, elas devem permanecer na vida escolar para ampliar a construção e expansão do conhecimento e fortalecer o Projeto Político-Pedagógico e sua relação com a comunidade e sua cultura.

Em termos de formação humana dos estudantes, as políticas e ações a serem implementadas devem priorizar a qualidade social da educação ao invés dos resultados vinculados aos índices educacionais, o que implica em flexibilizar ou reorientar o currículo e a avaliação em todas as escolas, priorizando a autonomia das redes de ensino, das modalidades de educação, respeitando a situação específica local, evitando a padronização e uniformização e afirmando a diversidade, a pluralidade e a diferença conforme nos garante a Constituição e a legislação educacional.

Os grupos hegemônicos no campo educacional têm determinado que durante a pandemia, as redes públicas e privadas de ensino devem cumprir prioritariamente os objetivos de aprendizagem e desenvolvimento da Educação Básica definidas na BNCC, adotando o ensino remoto, com o uso de tecnologias diversificadas, com ou sem mediação tecnológica. O que as diversas análises têm demonstrado é que, essas medidas têm servido, tão somente, para o cumprimento formal das 800 horas exigidas pela legislação, através do compartilhamento de conteúdos que, uma vez isolados das relações sociais que medeiam a práxis escolar, pouco contribuem para a reflexão crítica e formação humana dos estudantes. E, como apontamos aqui, essas medidas acabam criando uma cortina de fumaça sobre os reais problemas das redes de ensino, das escolas e das famílias.

Em nosso entendimento, essa orientação não dá conta de um processo educativo de efetiva qualidade em tempos de pandemia, período atípico vivenciado por todos, onde a defesa da vida de estudantes, educadores e suas famílias deveria ter valor central de referência para as políticas e práticas educacionais neste momento. Ela desconsidera o fato de que o modelo proposto promove:

1) a exclusão social e educacional dos estudantes, face às desigualdades com relação ao acesso às tecnologias para realização das atividades, responsabilizando os próprios excluídos dos direitos e das políticas, por sua condição de exclusão;

2) a restrição do Direito à Educação à aprendizagem de "conteúdos essenciais", reescritos pelos currículos oficiais e ratificados nos exames nacionais, limita o currículo a um padrão que fere a autonomia das escolas e docentes em fazerem suas escolhas curriculares, dialogando com as questões que marcam a realidade social, cultural, geográfica dos estudantes e mais ainda, não leva em consideração as desigualdades econômicas e sanitárias que têm grande influência sobre as atividades educativas nesse contexto. Ademais, os conteúdos essenciais da BNCC não dialogam com as questões que estão postas na realidade social (isolamento, medo de contaminação e mortes; perdas familiares, desemprego; ansiedade; ambiente de estudo inapropriado, etc.), cujas exigências ultrapassam a aquisição de habilidades e competências para a produção de indicadores nas provas padronizadas e requerem espaço de análises e debates nas escolas;

3) há uma intensificação da precarização do trabalho docente, uma vez que os professores/as estão sobrecarregados de exigências que desconsideram a realidade objetiva imposta pela pandemia a todos os indivíduos. A situação agrava-se pelo fato de que os professores não possuem os equipamentos tecnológicos necessários ou mesmo, um conhecimento mais profundo de uso das tecnologias para dar aulas. Na maioria dos casos, os professores fazem uso de seus equipamentos, uma vez que não há subsídio dos governos para essa garantia. Além do mais, há uma carga horária excessiva de trabalho que tem contribuído para o adoecimento docente, que decorre tanto do excessivo tempo em telas, como da 
dificuldade de articular as demandas do trabalho com as atividades domésticas, as dificuldades com a saúde na família e com as questões financeiras, sobretudo, no caso dos professores temporários e das escolas privadas, nas quais muitos passaram por redução de salários.

Em contraponto a essa orientação, temos apostado desde o início da pandemia num amplo debate sobre as definições que implicam as atividades escolares neste período emergencial. Nesse sentido, temos fortalecido a afirmativa de que é preciso garantir o diálogo e a participação ampliada dos diferentes seguimentos sociais nas decisões coletivas de orientação para a Educação, como estratégia para encontrar caminhos, a partir da interação entre as especificidades e diferenças de modo a produzir consensos que possibilitem enxergar alternativas viáveis a serem implementadas e que de fato atendam a todos os setores existentes no âmbito da Educação no país: redes públicas e privadas, escolas da cidade e do campo, de comunidades indígenas, quilombolas, tradicionais e camponesas.

Esse nos parece ser o nó crítico que a Educação enfrenta nestes tempos de pandemia, definir coletivamente as orientações, políticas e ações para o setor educacional de forma compartilhada, participativa, com a escuta qualificada dos diversos seguimentos, etnias, povos e comunidades, afirmando a autonomia das escolas, das redes de ensino e das modalidades de educação; estimulando a auto-organização e autodeterminação, assim como, valorizando a ampla sociocultural-pluriversidade, que constitui a sociedade brasileira, com suas especificidades territoriais regionais e locais; e evitando a padronização e uniformização dos resultados escolares.

Isto exige a criação de canais permanentes de comunicação com a comunidade educacional, incluindo as comunidades ligadas aos povos indígenas, quilombolas, tradicionais e camponeses, suas lideranças e organizações, a fim de que as decisões sobre suas vidas e sobre a educação sejam tomadas, considerando suas realidades e especificidades, seus anseios, temores e preocupações vivenciados em meio à pandemia; além de assegurar suas oitivas em processos que os envolvem, conforme as normativas internacionais das quais o Brasil é signatário, a exemplo da Convenção 169 - OIT, 1989/2003 cuja observância e cumprimento contribuiriam, sobremaneira, para a emancipação e autodeterminação dos distintos segmentos sociais: estudantes das redes públicas e privadas de ensino, do campo e da cidade, indígenas, quilombolas, camponeses, deficientes, entre outros, assegurando, como condição essencial, a vacinação de todos.

Por fim, chamamos a atenção para que os gestores dos sistemas educacionais procurem dedicar especial atenção aos dados concretos da realidade de suas redes de ensino, dos professores e alunos, trazendo-os para serem problematizados com as instâncias governamentais (município, estado e União), Conselhos e Ministério Público. Entendemos que, uma vez que os problemas enfrentados nesse período sejam expostos, eles apontam para essas instâncias, que há necessidade de um conjunto de políticas estruturantes que estão para além das políticas de educação, mas que têm efeitos sobre as escolas. A ausência dessas políticas nos municípios e a responsabilidade do Estado para com sua garantia, não podem ser negligenciadas pelo imediatismo dos resultados ilusórios, produzidos apenas para criar o marketing de uma boa gestão, quando na verdade, amplia-se o processo de marginalização dos sujeitos. É uma responsabilidade que os gestores públicos têm sobre si e devem exercê-la sob o compromisso ético dos princípios e fins das funções que ocupam em defesa dos interesses da população.

\section{REFERÊNCIAS}

AGÊNCIA BRASIL. Pesquisa Tic Kids online 2019. Disponível em:

https://agenciabrasil.ebc.com.br/tags/tic-kids-online. Acesso em: 10 nov. 2020.

BRASIL. Constituição (1988). Constituição da República Federativa do Brasil: promulgada em 05 de outubro de 1988. Brasília: Imprensa Oficial, 1988.

BRASIL. Lei n 9.394, de 20 de dezembro de 1996. Estabelece as Diretrizes e Bases da Educação Nacional. Brasília: Câmara Federal, 1996.

BRASIL. Base Nacional Comum Curricular. Educação é a Base. Brasília, DF: Ministério da Educação, 2017. CARTA ABERTA EM DEFESA DA EDUCAÇÃO DEMOCRÁTICA (CONTRA PROJETOS DE CENSURA À 
EDUCAÇÃO NACIONAL), Disponível em: http://www.anfope.org.br/wpcontent/uploads/2018/07/CARTA-Aberta-em-defesa-da-EDUCA\%C3\%87\%C3\%83ODEMOCR\%C3\%81TICA-.pdf. Acesso em: 13 fev. 2021.

CETIC.BR - CENTRO REGIONAL DE ESTUDOS PARA O DESENVOLVIMENTO DA SOCIEDADE DA INFORMAÇÃO (CETIC.BR). Disponível em: https://www.cetic.br/pesquisa/domicilios/. Acesso em 09 abr. 2020.

CRISPIN, Crisleine da Silva. FACCI, Marilda Gonçalves Dias. Significado Social, sentido pessoal e readaptação docente: reflexões à luz da psicologia histórico - cultural. In: $\mathrm{FACCl}$, Marilda Gonçalves Dias; URT, Sônia da Cunha. (Orgs.) Quando os professores adoecem: demandas para a psicologia da educação. Campo Grande, MS: Ed. UFMS, 2020.

FELIPE, Eliana da Silva. Do SAEB à BNCC: padronizar para avaliar. In: UCHÔA, Antônio Marcos da Conceição. LIMA, Átila de Menezes; SENA, Ivânia Paula Freitas de Souza. (Orgs.). Reformas educacionais: avanço ou precarização da educação pública? Diálogos Críticos. Volume 2. Porto Alegre, RS: Editora Fi, 2020. Disponível em: https://www.editorafi.org/793dialogos. Acesso em: 03 mar. 2021.

FONEC - FÓRUM NACIONAL DE EDUCAÇÃO DO CAMPO. Carta do Fórum Nacional de Educação do Campo - FONEC, Articulações, Comitês e Fóruns Estaduais de Educação do Campo e Apoiadores/as. Brasília. 2020. (digitalizado).

FREIRE, Paulo. Pedagogia do Oprimido. Brasília. 42 Edição. Paz e Terra. 2005.

MINISTÉRIO DA EDUCAÇÃO. Diretrizes Curriculares Nacionais para a Educação Básica. Disponível em: http://portal.mec.gov.br/docman/julho-2013-pdf/13677-diretrizes-educacao-basica-2013-pdf/file. Acesso em: 11 fev. 2021.

SANTOS, Clarice Aparecida dos, MOLINA, Mônica Castagna; HAGE, Salomão Antônio Mufarrej. Ensino Remoto e à Distância aprofunda as Desigualdades e não garante o Direito à Educação dos Povos Tradicionais e Camponeses em Tempos de Pandemia, Dez. 2020. Disponível em: https://anped.org.br/news/ensino-remoto-e-distancia-aprofunda-desigualdades-e-nao-garanteo-direito-educacao-dos-povos. Acesso em: 20 de fev. 2021.

SAVIANI, Demerval. MARSÍGLIA, Ana Carolina Galvão. Educação na Pandemia: a "falácia" do ensino remoto. COVID-19. Trabalho e saúde docente. In: ANDES-SN. Universidade e Sociedade 67. Pandemia da Covid-19 - Trabalho e saúde docente, Jan.2021. Disponível em:

https://issuu.com/andessn/docs/revista_us_67_web. Acesso em: 05 mar. 2021.

TAFFAREL, Celi Nelza Zulke. SOUSA, Érica Cordeiro Cruz (orgs). Dossiê: contribuição ao debate sobre o que fazer em educação em meio à pandemia do coronavirus. (COVID-19). LEPEL, GEPEC, UFBA - FACED, ANFOPE. Salvador. Julho de 2020. Disponível em: http://www.anfope.org.br/wpcontent/uploads/2020/07/DOSSI\%C3\%8A-CONTRIBUI\%C3\%87\%C3\%83O-AO-DEBATE-SOBRE-O-QUE-FAZEREM-EDUCA\%C3\%87\%C3\%830-vs-11-07-20-compactado.pdf. Acesso em: 05 mar.2021.

Este obra está licenciado com uma Licença Creative Commons Atribuição-NãoComercial 4.0 Internacional. 